\title{
A qualitative analysis of main cross-border balancing arrangements
}

\author{
R. A. C. van der Veen, A. Abbasy, and R. A. Hakvoort
}

\begin{abstract}
The integration of balancing markets, i.e. marketbased balance management arrangements, is regarded as an important next step in the development towards an Internal Electricity Market for Europe, and is expected to largely reduce the costs of real-time balancing by enhancing competition in balancing service markets. However, there is still a large knowledge gap on the possibilities and effects of balancing market integration. This paper contributes to filling up that gap by means of a qualitative assessment of the main alternative market arrangements for cross-border balancing. We evaluate the impact of seven main cross-border balancing arrangements on the basis of a set of ten high-level performance criteria. The analysis shows that although the net impact of the arrangements of ACE netting and a common merit order list can be expected to be positive, there are major uncertainties in impact related to the dependency on detailed balancing market design choices and power system and market conditions. The uncertainties and dependencies regarding the impact of balancing market integration call for a detailed analysis in each individual integration case.
\end{abstract}

Index Terms-balancing market, cross-border balancing, market integration

\section{NOMENCLATURE}

$\mathrm{ACE}=$ Area Control Error

$\mathrm{BEM}=$ Balancing Energy Market

$\mathrm{BRP}=$ Balance Responsible Party

$\mathrm{BSP}=$ Balancing Service Provider

$\mathrm{BSM}=$ Balancing Service Market

PTU $=$ Program Time Unit

$\mathrm{RCM}=$ Reserve Capacity Market

$\mathrm{TSO}=$ Transmission System Operator

\section{INTRODUCTION}

$\mathrm{I}_{\mathrm{o}}^{\mathrm{N}}$ today's liberalized power markets, even the power system operation service of balance management, i.e. the continuous balancing of power supply and demand to stabilize system frequency, becomes increasingly market-based. We define a balancing market as an institutional arrangement that

This work is supported by the Next Generation Infrastructures Foundation, and is part of the research project "Balance Management in Multinational Power Markets".

R. A. C. van der Veen is with Delft University of Technology, faculty of Technology, Policy and Management, 2628 BX, Delft, the Netherlands (email: r.a.c.vanderveen@tudelft.nl).

A. Abbasy is with Delft University of Technology, faculty of TPM, 2628 BX, Delft, the Netherlands (e-mail: a.abbasy@tudelft.nl).

R. A. Hakvoort is with Delft University of Technology, faculty of TPM, 2628 BX, Delft, the Netherlands (e-mail: r.a.hakvoort@tudelft.nl). establishes market-based balance management in a liberalized electricity market, and that consists of three main parts: balance responsibility, balancing service provision, and imbalance settlement.

In Europe, each country generally has its own 'balancing market design', i.e. its own unique combination of rules governing the roles of the Balance Responsible Parties (BRPs) to balance their portfolio and of the Balancing Service Providers (BSPs) to offer balancing services to the Transmission System Operator (TSO). The European Commission has expressed in the energy sector inquiry from January 2007 that current balancing service markets are highly concentrated and create entry barriers, that the enlargement of balancing zones will help enhancing competition, and that the harmonization of balancing market designs is an important step to achieve this [1]. For this reason, the Commission has also requested a study by the Catholic University of Leuven and Tractebel Engineering on interactions between balancing markets. Their final report from February 2009 gives recommendations on several balancing market design aspects and on a phased harmonization process of balancing markets. In addition, supported by an analysis of offered and activated balancing energy bids in Belgium and France, the report concludes that 'the implementation of a cross-border balancing market is a lucrative and achievable goal that does not entail unrealistic or overly expensive preconditions' [2]. Furthermore, the European Regulator's Group for Electricity and Gas (ERGEG) stresses that 'a lack of integration of balancing markets is a key impediment to the development of a single European electricity market' [3].

Viewing the above, it appears that balancing market integration is generally considered as a process with positive effects, notably those of enhanced competition and reduction of balancing costs. However, insufficient research has yet been conducted to support a conclusion of this kind, and a systematic analysis appears to be lacking completely. This paper aims to fill up the gap by means of a high-level qualitative analysis of balancing market integration. In this multi-criteria analysis, the effects of implementation of seven main market arrangements for cross-border balancing are assessed on the basis of ten high-level performance criteria.

The performance criteria and cross-border balancing arrangements will be introduced in resp. Sections III and IV. In Section $\mathrm{V}$, the results of the multi-criteria analysis are presented. Section VI gives the conclusions and recommendations that are drawn from this analysis. 


\section{PERformanCE CRITERIA}

The evaluation of the effects of balancing market integration requires a set of performance criteria. However, it is not easy to specify what defines a well-performing balancing market. To illustrate this, we will introduce here the basic market structure and concepts, as shown in Figure 1. Balancing Service Providers (BSPs) offer two types of balancing services to the TSO: reserve capacity and balancing energy. Balancing energy is delivered by real-time adjustment of balancing resources, whereas reserve capacity is procured by the TSO in order to obtain the option to activate balancing energy during the reservation period. Both types are offered in the form of bids, and selected in merit (price) order. Often, the price of the last selected bid becomes the price at which all bids are rewarded: the reserve capacity price, or the balancing energy price. Balance Responsible Parties (BRPs) submit energy programs to the TSO indicating planned production, consumption and trade. Program deviations are settled with an imbalance price, which is often directly based on the balancing energy price. For each Program Time Unit (PTU), (a) new balancing energy price(s) and imbalance price(s) are determined, based on the activated balancing energy bids, which thus influences the financial incentives for BRPs and BSPs to balance their portfolio and to submit balancing bids, respectively.

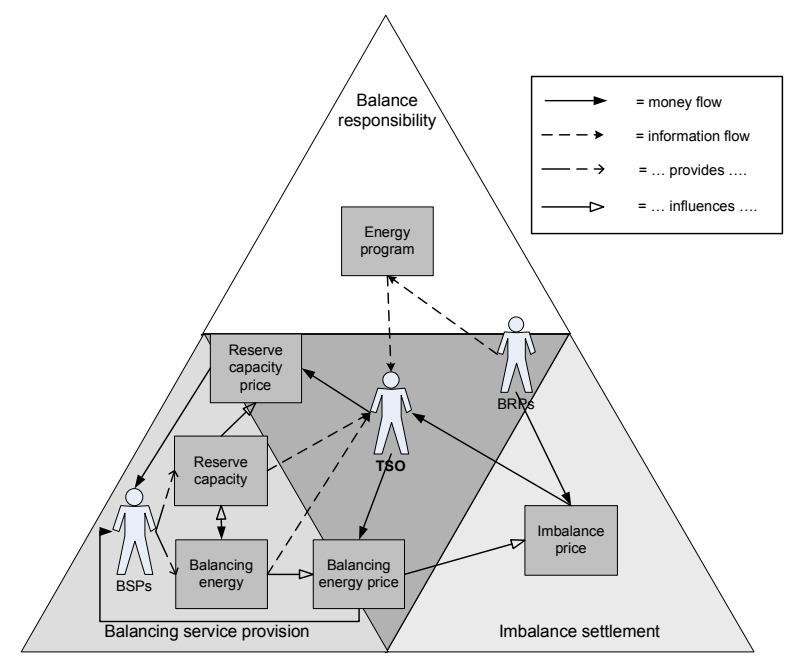

Fig. 1. Illustration of the basic balancing market structure and concepts

Now the balancing energy price and imbalance price appear to be quite logical performance criteria. However, they are actually indicators that should be interpreted by relating those prices to spot market prices. On a higher level, more general balancing market performance criteria can be defined from a system perspective, which are applied here to the qualitative analysis of cross-border balancing arrangements. They are listed in Table I.

The first two performance criteria, 'balance planning accuracy' and 'availability of balancing resources', are effectiveness criteria that concern the technical performance of balancing markets. Balance planning accuracy is the accuracy of energy programs of BRPs, which determines the size of the energy imbalance over the PTUs, and thereby influences technical performance. A lower availability of balancing resources means a larger chance that there are not enough resources to restore the system balance, or that the stability of the system frequency will reduce.

The next four criteria in Table I concern the economic efficiency of the balancing market. 'Allocative efficiency' is about utilizing the available balancing resources in an economically efficient way. 'Balancing Service Market (BSM) concentration' is about the number of BSPs and their market power in the BSMs. This criterion is closely related to the criterion of 'BSM price efficiency', which is determined by the cost-reflectivity of balancing service prices. The fourth economic criterion of 'operational efficiency' is about the minimization of the costs of transactions in the balancing market. We evaluate this criterion by considering the effect of arrangements on the height of the transactions costs.

Furthermore, there are two other high-level performance criteria which are not really economic criteria, but do affect economic balancing market performance: 'non-discrimination' and 'transparency'. Both are goals stated in the Electricity Directive 2004/54/EC: "Rules adopted by transmission system operators for balancing the electricity system shall be objective, transparent and non-discriminatory..." [4]. Nondiscrimination in the balancing market calls for equal balancing market rules for BRPs, BSPs, and TSOs. Transparency is reached through the availability of information, information symmetry between market players, and clarity of information.

Finally, there are two criteria that are only relevant for balancing market integration: 'integration costs' and 'efficiency of cross-border capacity allocation'. The integration costs are the one-time switching costs of implementing the cross-border balancing arrangement. Actually, this is more an indicator for the value of integration than a balancing market performance criterion. The efficiency of cross-border capacity allocation takes into account the economic effects of allocating cross-border capacity on different power markets, including BSMs.

TABLE I

SET OF BALANCING MARKET PERFORMANCE CRITERIA

\begin{tabular}{|l|l|}
\hline Performance criteria & Short description \\
\hline Balance planning accuracy & $\begin{array}{l}\text { Accuracy of energy programs, which } \\
\text { determines the system imbalance }\end{array}$ \\
\hline $\begin{array}{l}\text { Availability of balancing } \\
\text { resources }\end{array}$ & $\begin{array}{l}\text { Availability of resources for the } \\
\text { restoration of the system balance }\end{array}$ \\
\hline Allocative efficiency & $\begin{array}{l}\text { Overall economic efficiency of the } \\
\text { utilization of balancing resources }\end{array}$ \\
\hline BSM concentration & $\begin{array}{l}\text { Market concentration in the Balancing } \\
\text { Service Markets }\end{array}$ \\
\hline BSM price efficiency & $\begin{array}{l}\text { Cost-reflectivity of balancing service } \\
\text { prices in Balancing Service Markets }\end{array}$ \\
\hline Operational efficiency & $\begin{array}{l}\text { Height of transaction costs in the } \\
\text { balancing market }\end{array}$ \\
\hline Non-discrimination & $\begin{array}{l}\text { Equal balancing market rules for different } \\
\text { market players and control areas }\end{array}$ \\
\hline Transparency & $\begin{array}{l}\text { Information availability, symmetry and } \\
\text { clarity on rules and results }\end{array}$ \\
\hline Integration costs & $\begin{array}{l}\text { One-time switching costs of balancing } \\
\text { market integration }\end{array}$ \\
\hline $\begin{array}{l}\text { Efficiency of cross-border } \\
\text { capacity allocation }\end{array}$ & $\begin{array}{l}\text { The total economic value of the chosen } \\
\text { distribution of capacity between the } \\
\text { market vs. for balancing service exchange }\end{array}$ \\
\hline
\end{tabular}




\section{CROSS-BORDER BALANCING ARRANGEMENTS}

A fundamental element in the design of integrated (regional) balancing markets is the main market arrangement that is installed to enable the cross-border exchange of balancing services, which we will call cross-border balancing arrangement. We make the distinction between four basic arrangements: Area Control Error (ACE) netting, BSP-TSO trading, an additional voluntary pool, and a common merit order list, see Figure 2. The last three arrangements have been introduced by ETSO, as conceptual models for cross-border trade of reserves [5-6], or as balancing market integration steps [7]. The first arrangement of ACE netting has not, but it has been formulated and implemented as a separate integration step in the integration of the German balancing markets of transpower, 50Hertz and EnBW [8]. The arrangements can be considered for two or more control areas in the process of balancing market integration. Following [7], we will call this group of areas the 'balancing region'.

$A C E$ netting prevents that balancing energy services in different control areas are activated in opposite direction. In the UCTE zone of continental Europe, each control area is required to remove its Area Control Error to zero within fifteen minutes, by means of Load-Frequency Control. ACE netting is realized by netting the ACEs of different control areas, and redistributing the remaining error, resulting in reduced activation of balancing energy in those areas. This arrangement differs from the other ones in that the balancing service markets are not adapted themselves, but only the input for these markets.

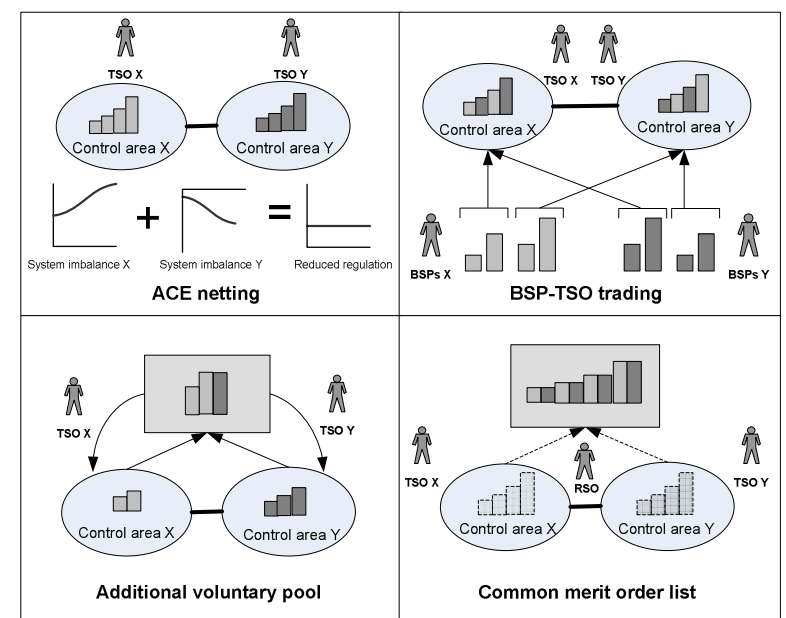

Fig. 2. Illustration of the four basic cross-border balancing arrangements

BSP-TSO trading means that BSPs can offer balancing services not only to the TSO of their own control area, but also to TSOs of other control areas in the balancing region. The implementation of this arrangement only requires the opening up of BSMs to bids of other areas, but harmonization of important design variables like PTU, market gate closure time and bid requirements will greatly facilitate the cross-border trade of balancing services.

An additional voluntary pool means the creation of an additional Balancing Service Market on the regional level, on which the TSOs of the cooperating control areas can offer balancing service bids to other TSOs on a voluntary basis.
This arrangement can take different forms, from bilateral trade to mutual sharing of bids.

A common merit order list is realized by the integration of the different Balancing Service Markets in the balancing region into one regional $\mathrm{BSM}$, creating one regional bid ladder, or merit order list. There will be one regional System Operator that activates balancing bids for maintaining the system balance of the entire balancing region.

The seven cross-border balancing arrangements that are incorporated in the multi-criteria analysis are 'ACE netting', 'BSP-TSO trading of balancing energy', 'BSP-TSO trading of reserve capacity', 'additional voluntary pool for balancing energy', 'additional voluntary pool for reserve capacity', 'common merit order list for balancing energy', and 'common merit order list for reserve capacity and balancing energy'. In Figure 3, they are positioned in a possible balancing market integration process. It must be remarked that there is no fixed order of integration steps; balancing market integration is in essence a reversible institutional change process.

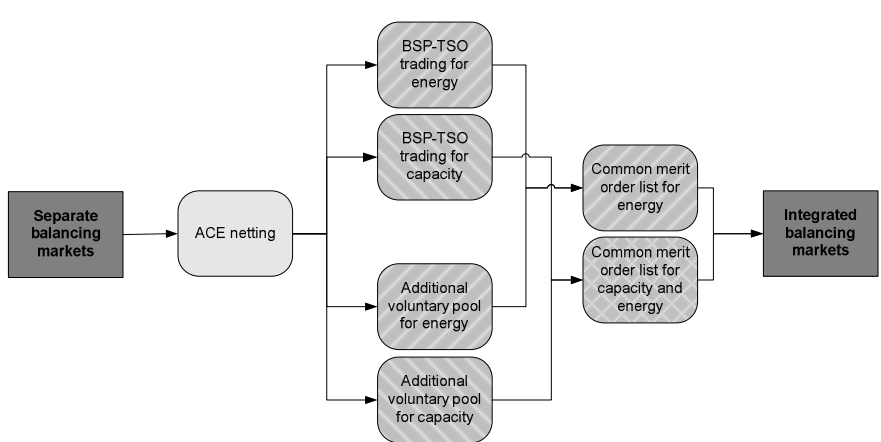

Fig.3. The seven cross-border balancing arrangements that are compared in the multi-criteria analysis, positioned in a conceptual balancing market integration process.

Due to the fundamental differences between reserve capacity and balancing energy, we do not only distinguish between basic arrangements, but also between reserve capacity exchange (cross-border trade) and balancing energy exchange. A common merit order list for reserve capacity alone is not considered, because this arrangement implies that there is also a balancing energy merit order list. BSP-TSO trading or an additional voluntary pool for both capacity and energy at the same time are also possible, but we have chosen to analyze the more simple and elementary options. For the same reason, possible combinations of arrangements, such as both an additional voluntary pool for capacity and BSP-TSO trading for energy, have not been incorporated.

The important distinction between the cross-border trade of reserve capacity and of balancing energy is that the first requires certainty on the availability of cross-border capacity for the entire contract period. We assume that cross-border capacity needs to be reserved for the cross-border trade of reserve capacity. In addition, we assume that cross-border capacity still remains after day-ahead and intraday auctions, meaning that balancing service exchange can be realized without cross-border capacity reservation, but to a lower extent. 


\section{MULTI-CRITERIA ANALYSIS}

In the multi-criteria analysis, the effects of the implementation of each of the seven cross-border balancing arrangements of Section IV on the ten performance criteria introduced in Section III are assessed qualitatively. This assessment is based on the consideration of the specific designs of the alternative cross-border balancing arrangements, and of the effects their implementation could have on the behaviour of Balance Responsible Parties and Balancing Service Providers, and therefore on balancing market performance. The assessed effects are relative to the performance of separate balancing markets. The analysis results are described per arrangement. After that, the impact on criteria that were not yet covered is shortly described.

\section{A. Effects of different cross-border balancing arrangements}

ACE netting: ACE netting will result in a large reduction of activated balancing energy bids in the involved control areas, and thereby improve balancing market effectiveness and competitiveness. As there is no specific cross-border trade transaction involved, and all areas benefit from this arrangement, there is no need for payment and an additional pricing mechanism, even though some areas will benefit more than others due to differently shaped bid ladder curves. A relevant detailed design choice is in what way the netted ACEs should be redistributed to the control areas. It may be best to redistribute proportional to the system imbalance of the control areas, in order to give appropriate incentives to BRPs and BSPs in the different balancing markets.

BSP-TSO trading of balancing energy: For this arrangement, an underlying design choice is whether or not BSPs are allowed to bid into two Balancing Energy Markets (BEMs) at the same time. Allowing this means high uncertainty on the effectiveness of bid activation by TSOs. We assume that this is not allowed, but that results in a shift of bids to the more expensive BEMs, and therefore also in higher balancing energy and imbalance prices in the cheaper balancing markets. Moreover, such large price differences between control areas may also lead to opportunities for gaming: BSPs that bid into more expensive BEMs, receive a high balancing energy price upon selection, do not deliver the energy, and only need to pay the lower imbalance price of the own control area. However, the harmonization of imbalance settlement designs could mitigate this potential for gaming.

BSP-TSO trading of reserve capacity: First, a general remark can be made about the cross-border trade of reserve capacity. In the UCTE synchronous zone, a minimum amount of capacity should be reserved within the own control area, according to the UCTE guidelines, namely $66 \%$ of the secondary control reserves, and $50 \%$ of the sum of secondary and tertiary control reserves [9]. This limits the scope of crossborder trade of this type of balancing service. Furthermore, a specific issue for BSP-TSO trading of reserve capacity is whether the TSO or the BSP reserves the cross-border capacity that is required for the reserve capacity exchange. In case of the latter, probably less exchange will occur. This arrangement reduces efficiency of cross-border capacity allocation, if it reduces the economic value of day-ahead trade more than the total balancing costs decrease in the balancing region.
An additional voluntary pool for balancing energy: For the additional voluntary pool, it is the TSO who decides on cross-border trade of balancing services, in contrast to BSPTSO trading, where the BSP decides (although not on the bid selection). TSOs will probably only share balancing energy bids that they will not need, and are out of price order otherwise balancing costs and imbalance prices in their area would increase. However, only in real-time the TSOs know about the exact size of the system imbalance and the corresponding demand for balancing energy, and cross-border trade in or near real-time may be technically hard to realize, or create unacceptable time delays in activation. This may be reason for TSOs to refrain from the exchange of balancing energy bids, which could lead to minimal impact of this arrangement. However, the pool could also be of a less voluntary nature. If indeed all unused bids are shared with other areas (which approaches the arrangement of the common merit order list), a significant change in BSP bidding behaviour may develop. If more bids are activated due to TSO-TSO trading, and the chance of activation is increased, BSP may be tempted to increase their bid prices, especially when exported bids are rewarded with a higher price resulting from the other market. Thus, the detailed design of this arrangement, the relative balancing energy price level in different balancing energy markets, and the level of balancing energy demand (system imbalance) and supply (bid volumes) in the different markets are important factors.

An additional voluntary pool for reserve capacity: Like BSP-TSO trading of reserve capacity, the trading potential in this arrangement is limited by the minimum reserve requirements of control areas and the need for available crossborder capacity. Here, it is definitely the importing TSO that should reserve the cross-border capacity, which may or may not be a point to consider, depending on its reliance on interconnection auction revenues. Anyway, this arrangement only allows for the cross-border trading of specific reserve capacity bids, and thereby also the trading of the corresponding balancing energy bids. This limits the impact of this arrangement on economic efficiency. Moreover, the required cross-border capacity reservation creates opportunity costs, depending on the general level of congestions on the interconnectors.

A common merit order list for balancing energy: ACE netting implicitly takes place in this arrangement, because the system balance is maintained regionally, by means of regional activation of balancing energy bids. The central activation also makes sure that the cheapest bids in the region are activated. This will greatly reduce the balancing service costs. The larger supply of bids and the lower demand for bids (caused by the ACE netting), may lead to enhanced competition. However, this arrangement will also affect BSP bidding behaviour. When there are large balancing energy price differences between areas, this creates more market opportunities for the BSPs in the cheaper areas. If there are ample balancing resources in the cheap areas, these BSPs could benefit from bidding somewhat below the price level of the more expensive areas, as a result of which overall price efficiency could reduce while allocative efficiency increases. Depending on the pricing mechanisms, this may also lead to higher balancing 
energy prices and imbalance prices for the cheap areas, compared to the situation of separate balancing markets.

A common merit order list for energy \& capacity: The existence of a common merit order list for reserve capacity implies that there is also a merit order list for balancing energy. The merit order list for reserve capacity is restricted by the national reserve requirements and the need for crossborder capacity, but assuming that cross-border capacity is reserved to enable meeting the national requirements in the regionally cheapest way, we can expect that the availability of balancing resources will actually increase. This is because the reserved cross-border capacity can in this arrangement also be utilized for optimized balancing energy exchange. Thus, this arrangement could largely increase allocative efficiency of Balancing Service Markets. However, the size of this increase would be limited when ample cross-border capacity remains for balancing energy exchange after cross-border intraday trade already without integration.

\section{B. Effects on different performance criteria}

In Figure 4, the relative impact of the different arrangements on availability of balancing resources, allocative efficiency, BSM price efficiency, and efficiency of cross-border capacity allocation is presented. The impact on the not yet discussed criteria is shortly described below.

Balance planning accuracy: The effect of the implementation of a cross-border balancing arrangement on the behaviour of Balance Responsible Parties is expected to be limited, even though imbalance prices will change.
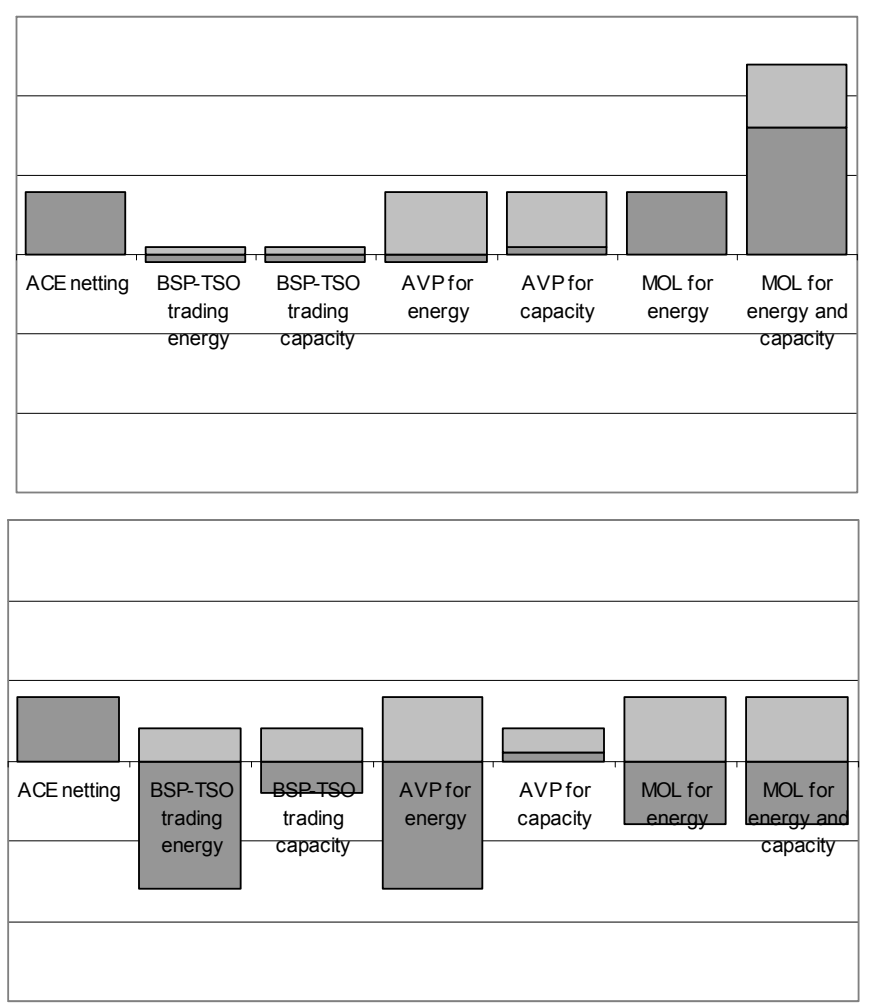

This is because BRPs generally try to schedule accurately in any case, and because the arrangements do generally not change the imbalance settlement design. The exception may be the common merit order list, where a regional design could be installed to complement the regional balance regulation.

Non-discrimination: Generally, non-discrimination increases, although only in a common merit order list the equality of market conditions for BSPs is certain to increase, due to integration of the Balancing Service Market(s).

Operational efficiency: The height of the transaction costs are expected to decrease for the common merit order list, to increase for ACE netting and a voluntary pool, and to remain the same for BSP-TSO trading, based on the change in complexity of the totality of balancing market rules.

Transparency: The transparency is generally expected to increase, but this depends on the clarity of the detailed crossborder balancing rules, and on information spreading.

Integration costs: Integration costs are only one-time costs, and are not expected to be very high, because the implementation of an arrangement is predominantly an institutional change. These costs will be lowest for ACE netting and BSP-TSO trading, higher for a pool, and highest for a merit order list.

\section{General results}

If we want to give a single assessment of the impact of different cross-border balancing arrangements on balancing market performance based on the analysis, we can add up the effects on the different performance criteria. In addition, the criteria should be given a certain weight.
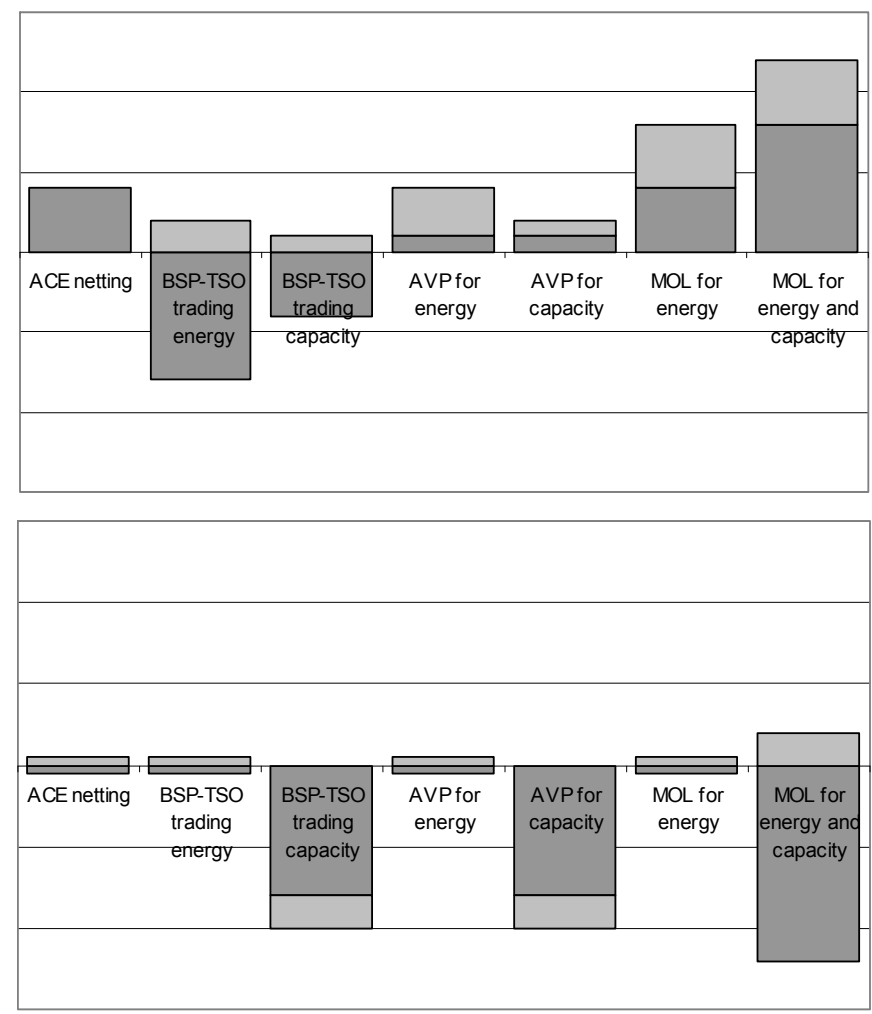

Fig. 4. Effect ranges of the cross-border balancing arrangements for the performance criteria of availability of balancing resources (top left), allocative efficiency (top right), BSM price efficiency (bottom left), and efficiency of cross-border capacity allocation (bottom right). AVP = additional voluntary pool; $\mathrm{MOL}=$ merit order list; 'capacity' = reserve capacity; 'energy' = balancing energy. If the dark bar and light bars lie on the same side of the $\mathrm{x}$-axis, the effect range is indicated by the light bar; otherwise, this range is indicated by the full length of both bars. 
We have given a weight of 'two' to availability of balancing resources, BSM concentration, BSM price efficiency, and socio-economic welfare of cross-border capacity allocation, and a weight of 'one' to the other criteria. This has resulted in the relative effect ranges given in Figure 5. One should keep in mind, however, that weighing is largely a subjective exercise depending on the views of the policy-makers and stakeholders.

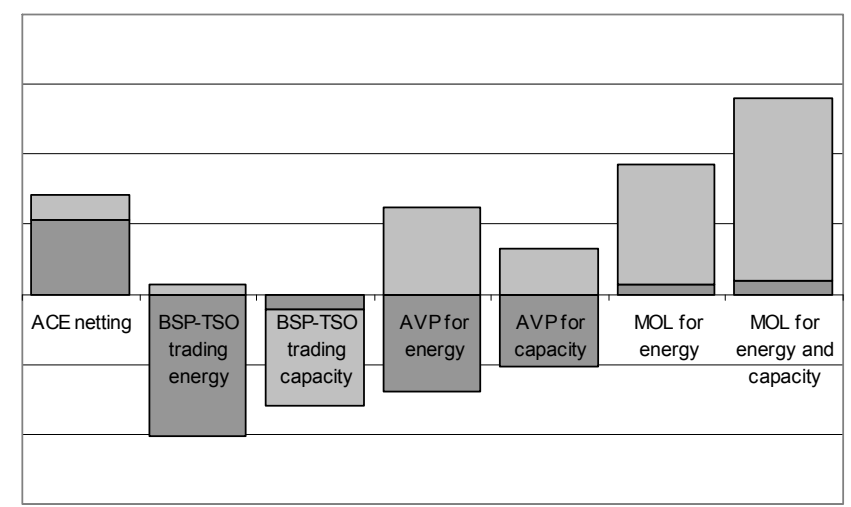

Fig. 5. Ranges of the net impact of main cross-border balancing arrangements on balancing market performance. $\mathrm{AVP}=$ additional voluntary pool; $\mathrm{MOL}=$ merit order list; 'capacity' = reserve capacity; 'energy' = balancing energy. If the dark bar and light bars lie on the same side of the x-axis, the effect range is indicated by the light bar; otherwise, this range is indicated by the full length of both bars.

In Figure 5, the effect ranges of the total impact of the arrangements on all the performance criteria are illustrated.

ACE netting is a no-regret option that is easily implemented and is certain to have a large positive impact. BSP-TSO trading rather has a large negative impact on balancing market performance than a positive one. For an additional voluntary pool, it is quite uncertain whether the impact will be positive or negative, and whether it will be a large or small impact. A merit order list is found to have a positive impact, but this could range from small to very large.

Because of the required reservation of cross-border capacity, the arrangements that concern the exchange of reserve capacity between control areas are more likely to have a negative impact. In addition, the size of the impact is generally smaller than for arrangements for balancing energy exchange, because the reservation enables only the exchange of specific balancing bids. The exception is a common merit order list for capacity and energy, where the reservation also enables a lot more cross-border balancing energy exchange.

The high level of uncertainty, as represented by the effect ranges, is caused by the dependency of the impact of the arrangements on both endogenous and exogenous factors. Endogenous factors relate to the (detailed) design of the balancing markets involved; exogenous factors to power system and market conditions in the balancing region. Important endogenous factors that the analysis revealed are the detailed configuration of the cross-border balancing arrangement, and the imbalance settlement design. Revealed exogenous factors include the size of system imbalances, level of supply of balancing resources, available cross-border capacity for balancing energy exchange without specific reservation, and the level of price differences between
Balancing Service Markets in different areas. All this influences the behaviour of BRPs and BSPs, which basically determines balancing market performance.

\section{CONCLUSIONS}

In general we may conclude from the qualitative analysis that ACE netting is a beneficial initial integration option, that BSP-TSO trading should not be aimed for, that the direction and size of the impact of an additional voluntary pool is quite uncertain, and that a common merit order list has a positive effect of uncertain magnitude.

The effect of the cross-border balancing arrangement on the behaviour of Balancing Service Providers is key, but this depends too much on the specific combination of detailed balancing market design choices and general power system and market conditions. Therefore, the high-level impact assessment of alternative arrangements is subject to large uncertainties.

Another identified complication is that even when the overall balancing market performance improves after integration, the performance could worsen in some of the control areas. This possibility should be taken into account.

All the existing uncertainties and dependencies makes that the value of balancing market integration can only be concluded from the consideration and analysis of specific balancing market integration cases, and it is therefore recommended to decision-makers to do so. In addition, we can recommend adopting ACE netting as a first integration step, but to await further steps until further analysis has proven their favourability for a specific group of control areas.

\section{REFERENCES}

[1] European Commission, "Inquiry pursuant to Article 17 of Regulation (EC) No $1 / 2003$ into the European gas and electricity sectors (Final Report)," COM(2006) 851 final, Jan. 2007. Available: http://eurlex.europa.eu/LexUriServ/LexUriServ.do?uri=COM:2006:0851:FIN:E $\mathrm{N}: \mathrm{PDF}$

[2] KU Leuven en Tractebel Engineering, "Study of the interactions and dependencies of balancing markets, intraday trade and automatically activated reserves," Final report, TREN/C2/84/2007, Feb. 2009.

[3] ERGEG, "Revised ERGEG Guidelines of Good Practice for Electricity Balancing Markets Integration (GGP-EBMI)," Ref: E09-ENM-14-04, Sep. 2009.

[4] European Commission, "Directive 2003/54/EC of the European Parliament and of the Council of 26 June 2003 concerning common rules for the internal market in electricity and repealing Directive 96/92/EC," Official Journal of the European Union, L 176/37-55, July 2003

[5] ETSO, "Current State of Trading Tertiary Reserves Across Borders in Europe," Nov. 2005.

[6] ETSO, "Key Issues in Facilitating Cross-Border Trading of Tertiary Reserves and Energy Balancing," May 2006.

[7] ETSO, "Balance Management Harmonisation and Integration - 4th Report," Jan. 2007.

[8] EnBW, transpower and Vattenfall, "Presentation of optimized Grid Control Cooperation," presentation, Sept. 2009.

[9] UCTE, "P1 - Policy 1: Load-Frequency Control and Performance [C]," version 3.0, revision 15, Apr. 2009. 